\title{
Regulation of mitochondrial DNA accumulation during oocyte growth and meiotic maturation in the mouse
}

\author{
Enas Mahrous ${ }^{1,2}$, Qin Yang ${ }^{1,2}$ and Hugh J Clarke Cl, $^{1,3}$ \\ Departments of ${ }^{1}$ Biology, ${ }^{2}$ Obstetrics and Gynecology, and ${ }^{3}$ Medicine, Centre for the Study of Reproduction, \\ McGill University, Research Institute of the McGill University Health Centre, Montréal, Quebec, Canada \\ Correspondence should be addressed to H J Clarke at F3.50, Royal Victoria Hospital, 687, av des Pins O, Montréal, QC, \\ Canada H3A 1A1; Email: hugh.clarke@mcgill.ca
}

\begin{abstract}
Oocytes accumulate an enormous quantity of mitochondrial (mt) DNA, and an insufficient amount of mtDNA may underlie some cases of poor oocyte quality leading to infertility. Little is known, however, about the mechanisms that govern the timing and regulation of mtDNA accumulation during oogenesis. We report, through analysis of the mtDNA content of individual oocytes of the mouse, that mtDNA accumulates steadily during oocyte growth to reach a value of $\sim 175000$ copies per cell. MtDNA content ceases to increase once oocytes reach full size and remains unchanged during meiotic maturation. To test whether mtDNA accumulation depends on oocyte growth, we inhibited growth in vitro in two ways - by exposing complexes comprising partially grown oocytes enclosed by granulosa cells to a chemical inhibitor of the phosphatidylinositol-3-kinase signaling pathway and by removing the surrounding granulosa cells from partially grown oocytes. Under both conditions, the oocytes fail to grow, but mtDNA accumulation is unaffected, indicating that the two processes can be mechanistically uncoupled. Quantitative analysis of the mRNAs encoding proteins required for mtDNA replication revealed that Polg (Polga) (polymerase- $\gamma, \alpha$-subunit), Polg2 (Polgb), and Tfam (transcription factor A, mitochondrial) increase during oocyte growth but then decrease after fully grown oocytes become transcriptionally silent as indicated by the non-surrounded nucleolusto-surrounded nucleolus transition. Thus, there is a correlation between the decline in the quantity of mRNAs encoding mtDNA replication factors in fully grown oocytes and the arrest of mtDNA accumulation in these cells, suggesting that the two events may be causally linked.

Reproduction (2012) 144 177-185
\end{abstract}

\section{Introduction}

Female germ cells manufacture a large stock of organelles and molecules that are inherited at fertilization by the embryo and direct its early development. Much attention has been focused on the abundance of mRNAs and the mechanisms by which these are stored and later translationally activated in a developmentally regulated manner. Equally impressive, however, is the substantial accumulation of mitochondrial $(\mathrm{mt})$ DNA (Dumollard et al. 2007, St John et al. 2010, Van Blerkom 2010). Although there is some variability among reports, particularly in humans, current data indicate that a mature fertilizable mammalian oocyte harbors 150000 250000 copies of mtDNA depending on the species (mouse (Piko \& Taylor 1987, Smith et al. 2005, Thundathil et al. 2005, Cao et al. 2007), human (Steuerwald et al. 2000, Reynier et al. 2001, Barritt et al. 2002, May-Panloup et al. 2005, Santos et al. 2006, Zeng et al. 2007), cow (May-Panloup et al. 2007), pig
(El Shourbagy et al. 2006), and rat (Kameyama et al. 2007)). As, at least in the mouse, primordial germ cells in the gonad contain about 2000 copies (Cao et al. 2007, Wai et al. 2008), it may be estimated that during mammalian oogenesis mtDNA content increases about 100-fold.

The accumulation of mtDNA in the oocyte serves at least two functions. First, mtDNA encodes components of the mitochondrial respiratory chain responsible for generating cellular ATP through oxidative phosphorylation, as well as tRNAs and rRNAs involved in transcription and translation of the gene products (Dumollard et al. 2007, St John et al. 2010, Van Blerkom 2010). Secondly, the amount of mtDNA remains constant or declines during the cleavage stages of embryogenesis, beginning to increase only near the time of implantation when the embryo begins to grow in size (Piko \& Taylor 1987, Thundathil et al. 2005, El Shourbagy et al. 2006, Kameyama et al. 2007, May-Panloup et al. 2007, St John et al. 2010). 
This indicates that, in contrast to the oocyte, the cells of the early embryo do not replicate mtDNA. The developing oocyte must therefore produce a large quantity so that each cell of the pre- or peri-implantation embryo inherits a sufficient number of mtDNA molecules to remain viable. Decreased mitochondrial function, which could in some cases be related to defective mtDNA replication, may underlie the agerelated decline in the developmental competence of oocytes (Van Blerkom 2009, 2010).

In somatic cells, mtDNA replication is uncoupled from nuclear DNA replication and instead occurs throughout the cell cycle (Bogenhagen \& Clayton 1977). Several key factors are thought to drive replication (Kanki et al. 2004, Pohjoismaki et al. 2006, Kang et al. 2007, Clay Montier et al. 2009, St John et al. 2010, Ylikallio et al. 2010), including transcription factor associated with mitochondria (TFAM), a high-mobilitygroup; HMG-type protein that coats the mtDNA in a manner possibly analogous to the histones and nuclear DNA; DNA polymerase- $\gamma$, consisting of a catalytic (POLG (POLGA)) and accessory subunit (POLG2 (POLGB)), that catalyzes synthesis of new mtDNA; nuclear respiratory factor 1 (NRF1); Twinkle, a helicase that has been proposed to be a 'licensing factor;' and mitochondrial single-stranded DNA-binding (mtSSB) protein. Although it seems likely that mtDNA replication in oocytes is similarly controlled, this has not been examined. Indeed, in contrast to the extensive studies on the 'bottleneck' mechanism that reduces mitochondrial heteroplasmy in individual oocytes (Cao et al. 2007, Shoubridge \& Wai 2007, Cree et al. 2008, Wai et al. 2008), almost nothing is known about the timing and regulation of mtDNA accumulation during oocyte development. Here, we have examined mtDNA accumulation during oocyte growth in vivo and in vitro and during meiotic maturation of the mouse.

\section{Results \\ Accumulation of mtDNA is correlated with oocyte growth}

To define the pattern of mtDNA accumulation during oocyte growth and meiotic maturation, we took advantage of the fact that a large cohort of oocytes in mice begins to grow soon after birth and reaches full size at about 3 weeks of age. We collected oocytes from mice of different ages, measured the diameter of each, and then transferred each oocyte individually into a microtube. To enable us to correct for differences in the efficiency of DNA purification between samples, a known quantity of plasmid DNA was added to each tube. DNA was purified, and each sample was analyzed using qPCR. We found that, although the quantity of mtDNA varied among oocytes of the same size, there was a continuous increase in mtDNA copy number as oocytes grew in size, reaching a maximum of $\sim 175000$ copies (Fig. 1A). Thus, mtDNA steadily accumulates during oocyte growth. The mathematical relationship that best fits the data shows that mtDNA content was proportional to a value less than the cube of the diameter (i.e. exponent is 1.9 rather than 3), which implies that increase in mtDNA during growth was less rapid than the increase in cellular volume.

We then tested whether mtDNA continues to accumulate after oocytes stop growing. The oocytes that begin to grow postnatally reach full size around day 18 and then stop growing. We collected oocytes from 18- and 24-day mice and then measured the diameter and mtDNA content of each oocyte as described earlier. We detected no differences in the average size or mtDNA copy number in the oocytes collected at the two ages (Fig. 1B). Although we cannot be certain that the oocytes collected at day 24 had completed growth by day 18 , this result strongly suggests that once oocytes stop growing, accumulation of mtDNA stops as well. We then tested whether mtDNA accumulates during meiotic maturation. Fully grown oocytes were collected and the diameter was measured. Half were placed individually in microtubes and stored, while the other half were incubated for $18 \mathrm{~h}$ to allow meiotic maturation and then collected. mtDNA copy number was measured as earlier. We found no difference between immature and mature oocytes (Fig. 1C). Taken together, these results indicate that mtDNA accumulates during the growth phase of oocyte development but stops when oocytes reach full size.

\section{Accumulation of mtDNA is mechanistically uncoupled from oocyte growth}

To study whether the correlation between mtDNA accumulation and oocyte growth reflected a mechanistic link, we measured the mtDNA content of oocytes grown in vitro under different conditions. Granulosa-oocyte complexes (GOCs) were isolated from preantral follicles obtained from 12-day animals. The granulosa cells were removed from half of them and the diameter of the oocyte was measured. The remaining GOCs were cultured on collagen-coated membranes for 7 days, after which the granulosa cells were removed and the oocyte diameter measured. MtDNA copy number of the oocytes was determined. The results showed that, under these culture conditions, the oocytes grew and mtDNA copy number increased by about $50 \%$ (Fig. 2A).

We then used two strategies to test whether the increase in mtDNA copy number was dependent on oocyte growth. First, we incubated the GOCs in the presence of LY294002, a chemical inhibitor of the phosphatidylinositol-3-kinase (PI3K) signaling pathway whose activity has been implicated in oocyte growth (Zheng et al. 2012). After 7 days of culture, the granulosa cells were removed and the diameter and mtDNA 

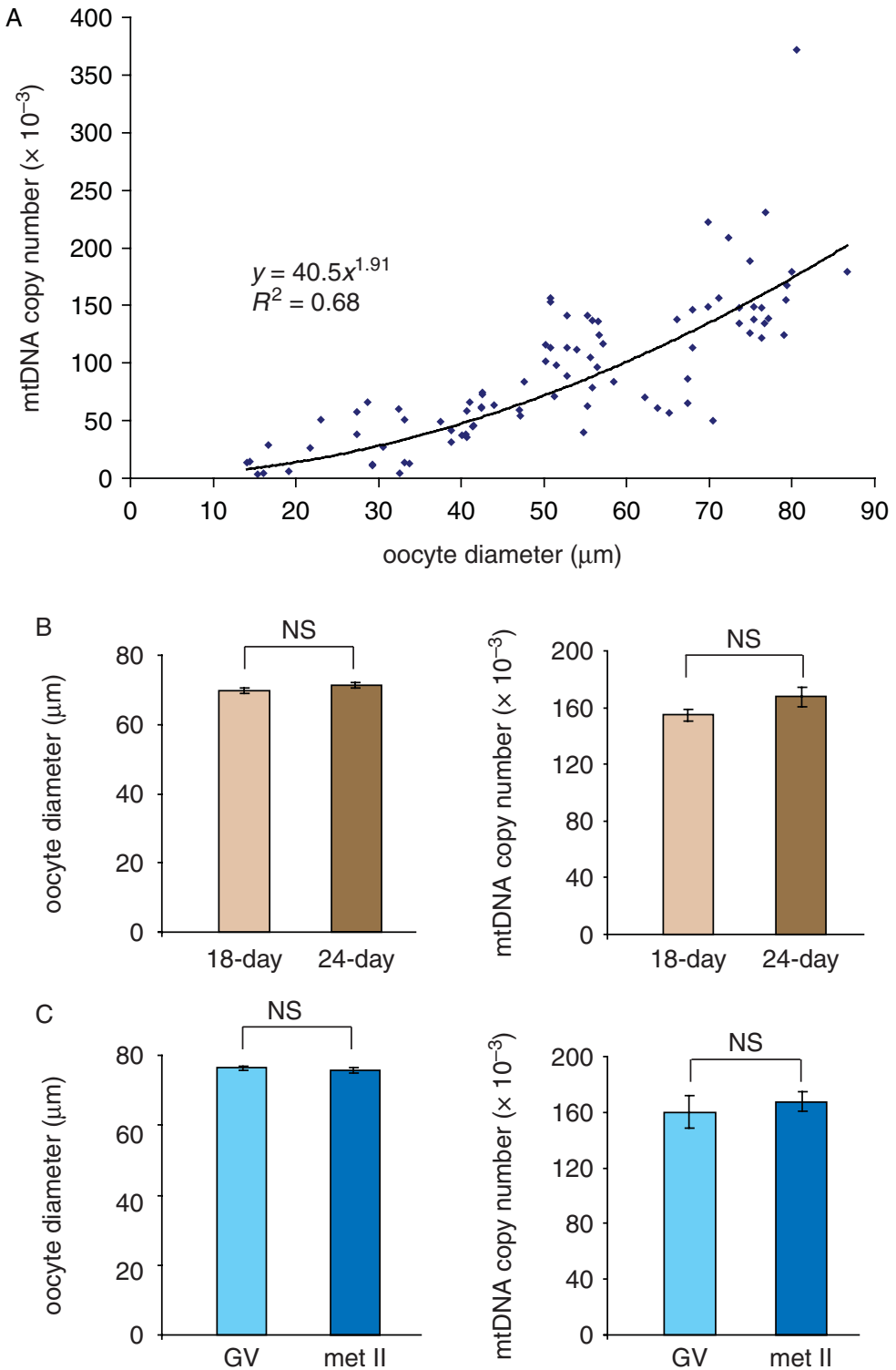

Figure 1 Accumulation of mtDNA during oocyte growth and meiotic maturation. (A) Oocytes at different stages of growth were removed from the ovarian follicle, the diameter was measured, and mtDNA content was determined using qPCR. Each point represents an individual oocyte. (B) Immature oocytes were obtained from mice of the indicated ages, the diameter was measured, and mtDNA content was determined using qPCR. (C) Immature oocytes were isolated from 20- to 22-day mice. One portion (GV) was analyzed immediately as in (B). The remainder were incubated overnight to allow meiotic maturation and those that emitted a polar body (met II) were analyzed as earlier. For both (B) and (C), bars show mean values and S.E.M. of three independent replicates. No significant differences (NS) in mean diameter or mtDNA content were detected $(t$-test, $P<0.05)$. content of oocytes were determined. Because the diameter and mtDNA content of the starting population of oocytes (i.e. day 0 of culture) varied among experiments, we normalized the oocyte diameter and mtDNA in each experiment to the values recorded at the start of the culture (i.e. day 0). We found that oocytes incubated in LY294002 failed to grow, confirming the essential role of $\mathrm{PI} 3 \mathrm{~K}$ in growth (Fig. 2B). In contrast, mtDNA accumulated to the same extent in the growthinhibited oocytes as in controls.

Next, because oocyte growth depends on physical interaction between the oocyte and its companion granulosa cells (Herlands \& Schultz 1984), we collected GOCs from 12-day mice and removed the granulosa cells from a portion. Following a 7-day culture, the diameter and mtDNA copy number of the granulosaenclosed and granulosa-free oocytes were measured as earlier. Consistent with the previous results, the granulosa-free oocytes did not grow. Nevertheless, mtDNA accumulated to the same level to that of granulosa-enclosed oocytes (Fig. 2C). Taken together, these results indicate that mtDNA accumulation is not mechanistically coupled to oocyte growth.

\section{Accumulation of mtDNA in growing oocytes is correlated with elevated quantities of mRNAs encoding essential replication factors}

As accumulation of mtDNA was not dependent on oocyte growth, we sought other factors that might account for the correlation of these two processes. As discussed in the Introduction section, mtDNA replication requires several nuclear-encoded proteins, including TFAM, NRF1, and POLG, which contains $\alpha$ and $\beta$ subunits. Oocytes at progressively more advanced stages of growth were obtained from 12-, 15-, 18-, and 21-day 
mice and the amount of the mRNAs encoding these proteins was quantified using qPCR.

We observed that the quantity of Actb (encoding $\beta$-actin) progressively increased from 12 to 18 days and
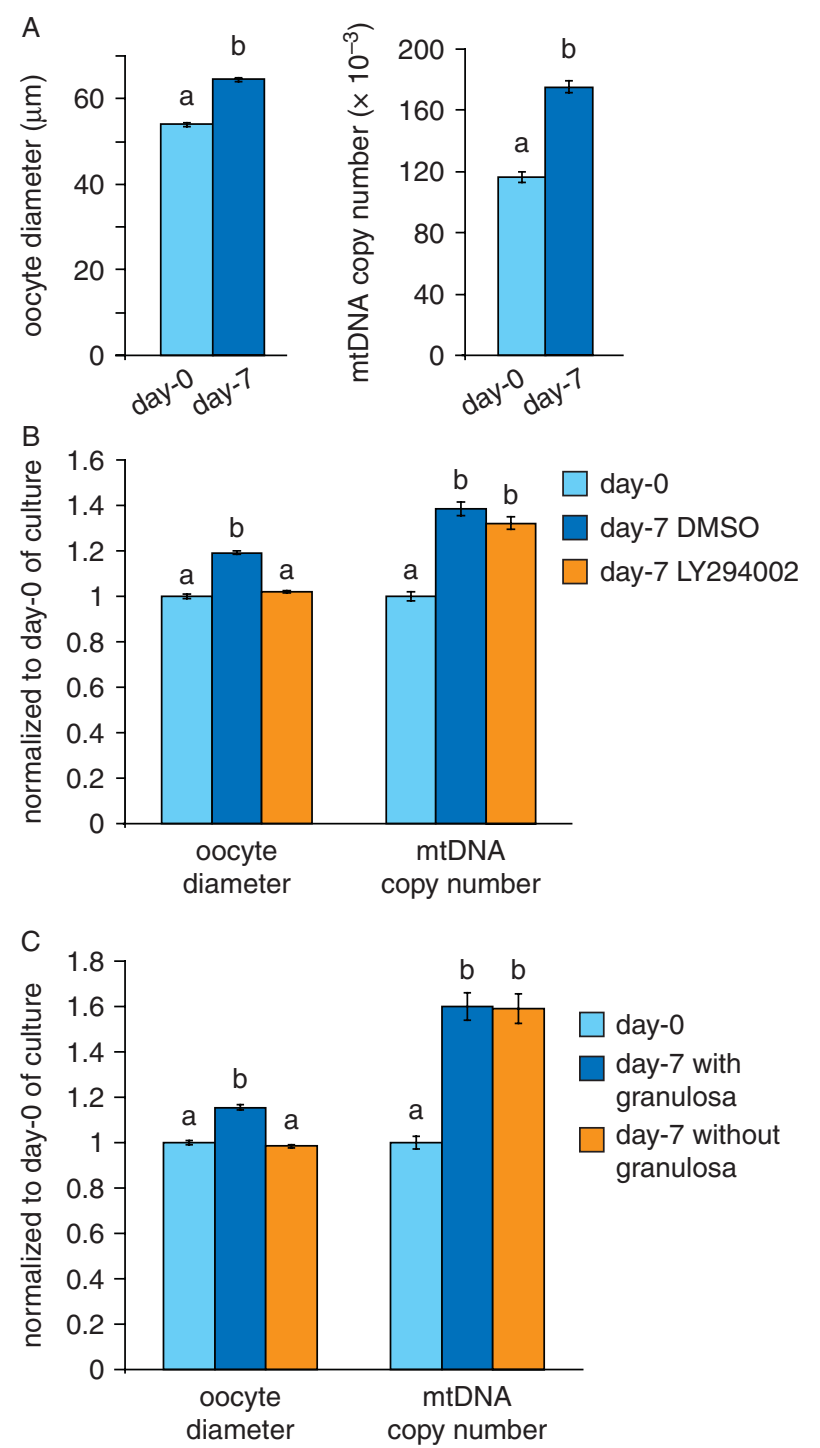

Figure 2 Accumulation of mtDNA during oocyte growth in vitro. (A) Granulosa-oocyte complexes (GOCs) were harvested from 12-day mice. The granulosa cells were removed from one portion and the diameter was measured. The remaining GOCs were incubated for 7 days, after which the oocyte diameter was measured. MtDNA content of both groups was then measured in the same qPCR. Mean and S.E.M. of five independent replicates are shown. Different letters above bars indicate a statistically significant difference ( $t$-test, $P<0.05$ ). (B) GOCs were harvested and processed as in (A), except that GOCs were incubated in the

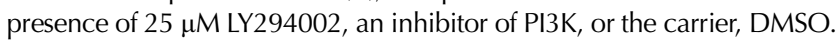
Results are normalized to day- 0 values because the initial diameter and mtDNA content of oocytes varied among different groups of mice. Mean and S.E.M. of four independent replicates are shown. (C) As in (A), except that the granulosa cells were removed from a portion of the oocytes before they were placed in culture. Mean and S.E.M. of four independent replicates are shown. For (B) and (C), different letters above bars indicate a statistically significant difference (one-way ANOVA with Tukey's HSD test). remained unchanged between 18 and 21 days (Fig. 3A). We also observed a small increase between 12 and 15 days in the amount of Nrf1, which subsequently remained unchanged. In contrast, the quantity of Polg, Polg2, and Tfam increased from 12 to 15 days but then decreased significantly in oocytes obtained from 18 and 21-day mice. Hence, near or at the end of oocyte growth, the quantity of these mRNAs declined.

It is known that after oocytes reach full size, their transcriptional activity declines significantly and that this is correlated with a change in the conformation of the chromatin, from a relatively dispersed pattern termed non-surrounded nucleolus (NSN) to a more condensed pattern termed surrounded nucleolus (SN). To test whether the decrease in Polg, Polg2, and Tfam might be linked to transcriptional arrest, we collected oocytes from 18-day mice, anticipating that, at this age, the oocytes would be undergoing the NSN-SN transition. Oocytes were stained with Hoechst 33342, which penetrates membranes of living cells, examined using fluorescence microscopy, and separated into NSN and $\mathrm{SN}$ groups. We then compared the amount of the same mRNAs in these two groups. We found that Tfam and Polg were significantly decreased in the NSN oocytes compared with the SN oocytes. Thus, when oocytes reach full size and transcription stops (or decreases), the amount of mRNA encoding specific mtDNA replication factors rapidly declines.

\section{Discussion}

We report four principal findings: mtDNA accumulates steadily in growing oocytes of the mouse, mtDNA does not accumulate in fully grown or maturing oocytes, mtDNA accumulation is mechanistically uncoupled from oocyte growth, and the arrest of mtDNA accumulation in fully grown oocytes is correlated with a decrease in the quantity of mRNAs encoding mtDNA replication factors.

Previous studies have demonstrated that fully grown oocytes harbor a large amount of mtDNA, ranging in mice from about 150000 to 175000 copies, and our results confirm these earlier reports. However, until now, little was known about the timing or control of mtDNA accumulation in oocytes. Our results indicate that mtDNA accumulation is correlated with oocyte growth, although possibly less rapidly than the increase in cellular volume. The link between mtDNA accumulation and growth in oocytes may be compared with the pattern in somatic cells, where mtDNA replication occurs throughout the cell growth cycle (Bogenhagen \& Clayton 1977). In this context, it is intriguing to note that, following fertilization, mtDNA content remains constant until it begins to increase near the time of implantation, which corresponds to the time that the embryo begins to increase in mass. These results taken together suggest that a link exists between the signals 

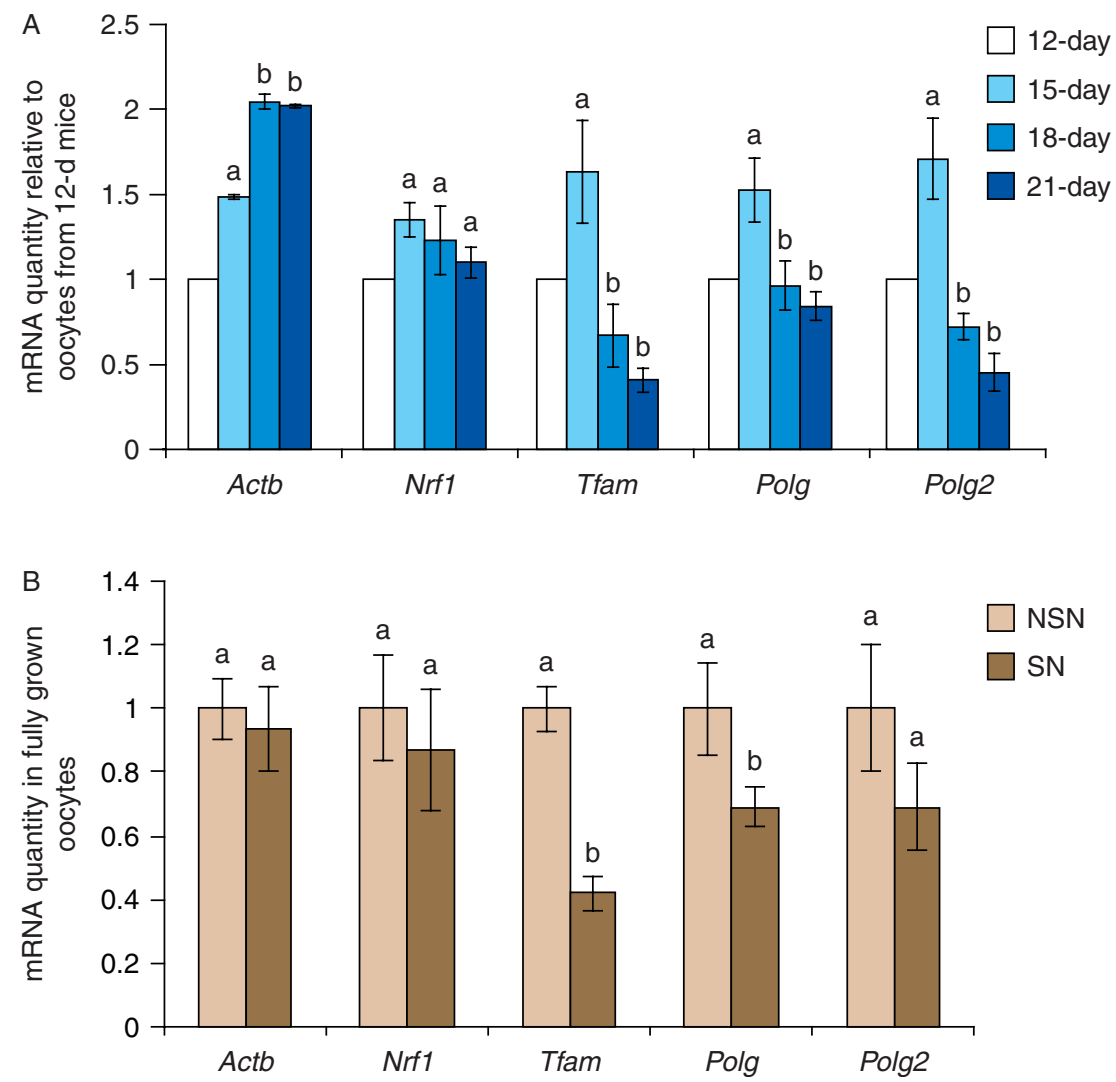

Figure 3 Amount of mRNA encoding proteins implicated in mtDNA replication at different stages of oocyte growth. (A) Oocytes were collected from mice of the indicated ages and the amount of each mRNA was determined using qPCR. Results are normalized to values at 12-day. Mean and S.E.M. of three independent replicates are shown. Different letters above histograms indicate a statistically significant difference (one-way ANOVA with Tukey's HSD test). (B) Oocytes were collected from 18-day mice, stained using Hoechst 33342, and classified as NSN or SN. The relative amount of the indicate mRNAs was measured in each group by qPCR. Results are normalized to the NSN group. Mean and S.E.M. of three independent replicates are shown. Different letters above histograms indicate a statistically significant difference ( $t$-test, $P<0.05)$.

that stimulate cellular growth (the oocyte in this case) and mtDNA accumulation respectively.

Despite the link between oocyte growth and mtDNA replication, we found using two independent methods that these could be mechanistically uncoupled. First, we used a chemical inhibitor of PI3K signaling activity, which has been implicated in both oocyte and granulosa cell development (Zheng et al. 2012). In the oocyte, PI3K has been implicated in growth on the basis of evidence that Kit ligand, acting on Kit receptors on the oocyte plasma membrane, stimulates oocyte growth in vitro. However, this role of PI3K has not been tested using chemical inhibitors, and oocytes lacking an important mediator of its signaling activity, 3-phosphoinositidedependent protein kinase 1 (PDK1), appear to grow to full size (Zheng et al. 2010). In the granulosa, PI3K may regulate proliferation and other aspects of differentiation. Our results indicate that oocyte growth in vitro requires $\mathrm{PI} 3 \mathrm{~K}$ signaling in one or both cell compartments. Secondly, we removed the granulosa cells that surround the oocyte. This prevents transfer of nucleotides and amino acids (and other small molecules) from the granulosa to the oocyte that normally occurs via the gap junctions that connect them and inhibits growth (Herlands \& Schultz 1984). Under both experimental conditions, however, mtDNA continued to accumulate despite the virtually complete arrest of oocyte growth. We suggest that a general growth-promoting signal may activate several downstream effector pathways, which independently regulate different aspects of the oocytegrowth program, including the increase in cell size and mtDNA replication.

A small family of regulatory proteins drive mtDNA replication in somatic cells and it is likely that these also function in oocytes. POLG, POLG2, and TFAM are of particular interest because the first two constitute the mtDNA-specific polymerase and newly replicated mtDNA is unstable unless it combines with TFAM in a nucleoprotein complex. Previous data that have suggested that TFAM might be a limiting factor in mtDNA replication in mammalian oocytes and embryos. In the pig, although Tfam declines during oocyte maturation (Spikings et al. 2007), both TFAM (Antelman et al. 2008) and mtDNA (Spikings et al. 2007) accumulate during this time. Additionally, as discussed earlier, mtDNA replication resumes in embryos near the time of implantation (Piko \& Taylor 1987, Ebert et al. 1988, Kameyama et al. 2007, May-Panloup et al. 2007); in mouse and cow, this is correlated with a sharp increase in the quantity of Tfam (Smith et al. 2005, Thundathil et al. 2005, May-Panloup et al. 2007).

Our finding that Polg, Polg2, and Tfam declined following the arrest of transcription in fully grown oocytes implies that these mRNAs are unstable in mouse oocytes at this stage. This does not rule out the presence of a stable pool of protein; however, the 
stability of POLG and POLG2 has to our knowledge not been reported, and available antibodies are not sufficiently sensitive to detect them in mouse oocytes by immunoblotting. TFAM appears to be rapidly degraded unless it is associated with mtDNA (Ekstrand et al. 2004, Kanki et al. 2004, Kang et al. 2007), which would likely prevent accumulation of a pool of free TFAM in transcriptionally active oocytes. One speculative possibility is that, as a consequence of transcriptional silencing, fully grown oocytes may possess insufficient quantities of proteins driving mtDNA replication to enable continued mtDNA accumulation (Fig. 4).

Our results show that the process of mtDNA accumulation is developmentally regulated in oocytes, but it is not yet clear whether the amount that accumulates is tightly regulated. In somatic cells, either too little or too much mtDNA can be harmful to cell health (Clay Montier et al. 2009, Ylikallio et al. 2010). In mammalian oocytes, comparing data obtained from different species indicates that, although the amount of mtDNA (and the number of mitochondria) seems to roughly correspond to the size of the oocyte, within a species there is considerable variability among individual oocytes (Piko \& Taylor 1987, Kameyama et al. 2007, May-Panloup et al. 2007, Shoubridge \& Wai 2007).
Moreover, a recent study in the mouse indicates that oocytes containing as few as 50,000 copies of mtDNA (about $1 / 4-1 / 3$ of the normal value) can give rise to healthy embryos (Wai et al. 2010). Further work will be needed to establish whether oocytes indeed manufacture substantially more mtDNA and mitochondria than are needed for their own or embryonic development.

\section{Materials and Methods}

\section{Animals}

All experiments were performed using CD-1 female mice (Charles River Canada, St-Constant, QC, Canada) in compliance with the regulations and policies of the Canadian Council on Animal Care and were approved by the Animal Care Committee of the Royal Victoria Hospital.

\section{Collection and culture of immature oocytes}

To obtain growing and fully grown oocytes, ovaries were removed from mice between 5- and 24-day of age. For mice up to 15-day, the ovaries were transferred to HEPES-buffered minimum essential medium (MEM-HEPES, pH 7.2) supplemented with collagenase type I $(1 \mathrm{mg} / \mathrm{ml}$; Worthington Biochemical, Lakewood, NJ, USA), trypsin (0.05\%; Sigma

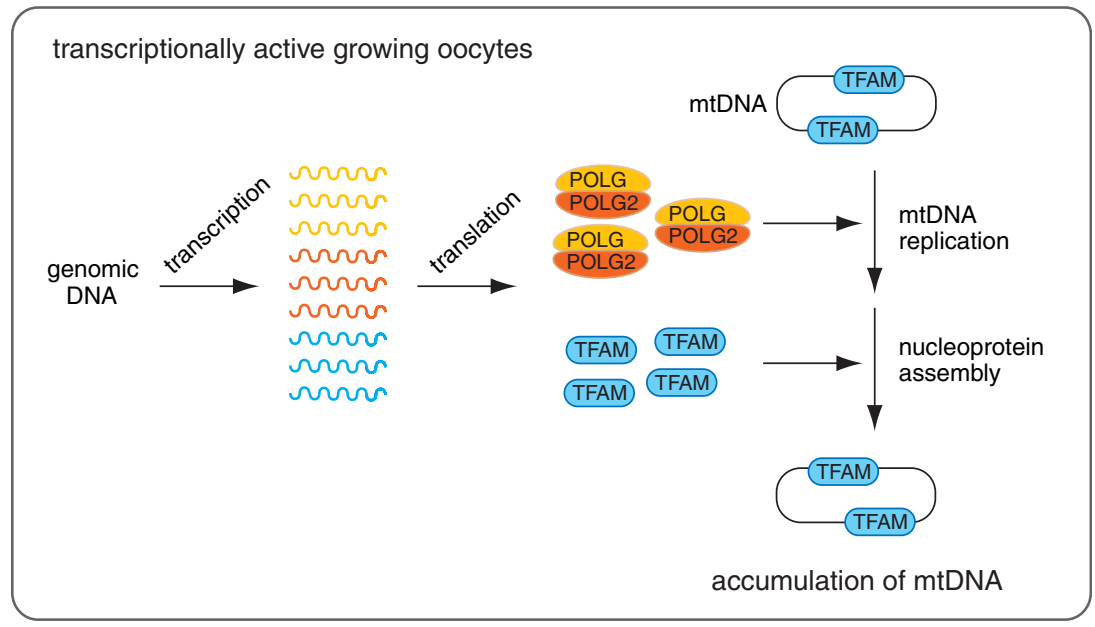

transcriptionally inactive fully grown oocytes

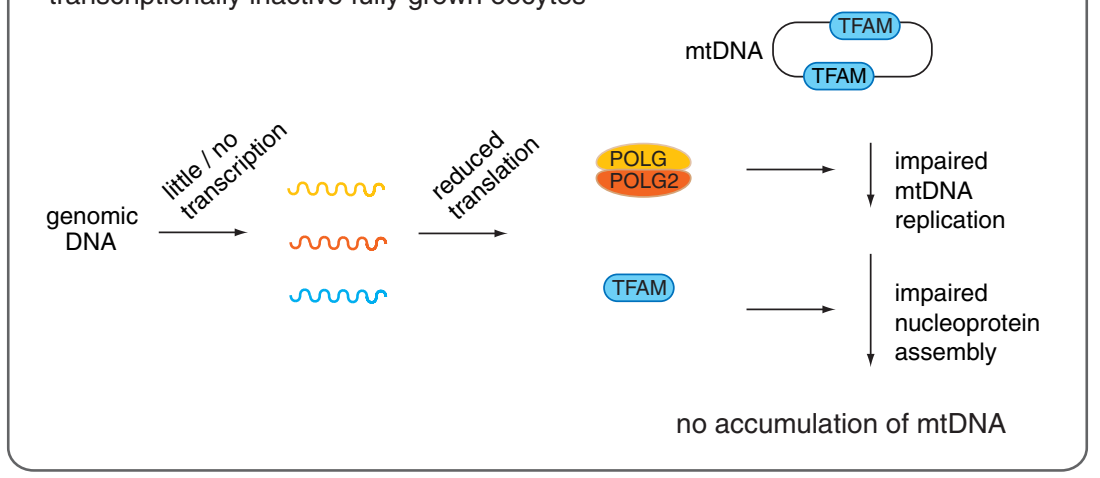

Figure $4 \mathrm{~A}$ model of mtDNA replication during oocyte growth. Transcriptionally active oocytes continuously produce mRNAs encoding POLG, POLG2, and TFAM (as well as other proteins) that replicate mtDNA and assemble it into a stable nucleoprotein. Hence, mtDNA accumulates. When fully grown oocytes stop or greatly reduce transcriptional activity, the existing mRNAs become depleted, meaning that insufficient new proteins can be synthesized to replicate mtDNA and/or stabilize the newly replicated mtDNA. Hence, mtDNA ceases to accumulate. 
Chemicals, Windsor, ON, Canada), and DNase $(0.02 \mathrm{mg} / \mathrm{ml}$; Sigma). Ovaries were torn into fragments and pipetted up and down using $1000-\mu \mathrm{l}$ tips and then left for $30 \mathrm{~min}$ at $37^{\circ} \mathrm{C}$. Using a mouth-controlled pipette, GOCs were collected and washed with fresh MEM-HEPES. When granulosa-free oocytes were required, the granulosa were removed by drawing the GOCs in and out of a narrow-bore pipette. For mice older than 18-day, the ovaries were placed in MEM-HEPES medium supplemented with sodium pyruvate $(28 \mu \mathrm{g} / \mathrm{ml}$; Sigma), penicillin G $(63 \mu \mathrm{g} / \mathrm{ml}$; Sigma), streptomycin $(50 \mu \mathrm{g} / \mathrm{ml}$; Sigma), and BSA (1 mg/ml; Sigma) at $37^{\circ} \mathrm{C}$, and the follicles were punctured using a 30-gauge needle. Oocytes surrounded by cumulus cells were collected. When required, the cumulus cells were removed as earlier.

To grow oocytes in vitro, GOCs isolated as described earlier from 12-day mice were transferred to Costar Transwell-COL membrane inserts $(3.0 \mu \mathrm{m}$ pore size; Ultident, Montreal, QC, Canada) in six-well cluster dishes, each well containing $4 \mathrm{ml}$ MEM-NaHCO ${ }_{3}$ supplemented as earlier and also containing cilostamide (10 $\mu \mathrm{M}$; Sigma) to prevent spontaneous meiotic maturation and $40 \mu \mathrm{l}$ insulin-transferrin-selenium (Sigma). Complexes were cultured for 7 days at $37^{\circ} \mathrm{C}$ in a humidified atmosphere of $5 \% \mathrm{CO}_{2}$ in air (30 complexes per well). The medium $(1.5 \mathrm{ml})$ was changed every second day.

To allow meiotic maturation in vitro, fully grown immature oocytes were transferred to $\mathrm{NaHCO}_{3}$-buffered MEM and incubated for $18 \mathrm{~h}$. At the end of the incubation period, oocytes with a visible polar body were washed in MEM-HEPES and used for analysis.

\section{Measurement of oocyte diameter and analysis of chromatin configuration}

Oocytes were placed individually in a $15 \mu$ drop of MEMHEPES medium using a 72-well Terasaki plate (VWR Scientific, Montreal, QC, Canada) covered by mineral oil $(\sim 5 \mu \mathrm{l})$ to prevent medium evaporation. The diameter of each oocyte excluding the zona pellucida was measured using the $40 \times$ objective of an inverted Zeiss LSM 510 confocal microscope. To determine chromatin configuration, oocytes were briefly stained using $1 \mu \mathrm{g} / \mathrm{ml}$ Hoechst 33342, then transferred to Terasaki plates as earlier, and examined using the confocal microscope.

\section{Preparation of rabbit globin cDNA and mt-ND1 standards for quantitative PCR}

Rabbit mRNA (Sigma) was converted to cDNA and genomic DNA was isolated from mouse tail using standard procedures. They were subjected to PCR amplification using the primers presented in Table 1. Amplified products were purified and recovered from agarose gels and then inserted into the pDrive cloning vector using the Qiagen PCR Cloning Kit (Qiagen) following the manufacturer's directions. Ligated products were used to transform $\mathrm{DH} 5 \alpha$ cells and the inserted DNA was sequenced to confirm its identity. Following bacterial growth and plasmid purification, plasmid DNA was quantified using a NanoDrop spectrophotometer and the copy number was determined using the following formula: number of molecules
Table 1 Primer sequences used for PCR amplification.

\begin{tabular}{|c|c|c|}
\hline Gene & Primers & $\begin{array}{l}\text { Product } \\
\text { size }(n t)\end{array}$ \\
\hline Rabbit & 5'-GTGGGACAGGAGCTTGAAAT-3' & 257 \\
\hline globin & 5'-GCAGCCACGGTGGCGAGTAT- $3^{\prime}$ & \\
\hline$m t-N D 1$ & $\begin{array}{l}5^{\prime} \text {-CGATTAAAGTCCTACGTGATCTGA-3' } \\
5^{\prime} \text {-CTGGGAGAAATCGTAAATAGATAGAAA-3' }\end{array}$ & 80 \\
\hline Actb & $\begin{array}{l}5^{\prime} \text {-GCTGTGCTATGTTGCTCTAG-3' } \\
5^{\prime} \text {-ATCGTACTCCTGCTTGCTGA-3' }\end{array}$ & 445 \\
\hline Nrf1 & $\begin{array}{l}5^{\prime} \text {-TCTCACCCTCCAAACCCAAC- }{ }^{\prime} \\
5^{\prime} \text {-CCCGACCTGTGGAATACTTG-3' }\end{array}$ & 254 \\
\hline Tfam & $\begin{array}{l}\text { 5'-CATTTATGTATCTGAAAGCTTCC-3' } \\
5^{\prime} \text {-CTCTTCCCAAGACTTCATTTC-3 }{ }^{\prime}\end{array}$ & 171 \\
\hline Polg & $\begin{array}{l}\text { 5'-CCTAAGCTCATGGCACTGAC-3' } \\
5^{\prime} \text {-TGCTGCTTCCCCTGTTCAAG-3' }\end{array}$ & 202 \\
\hline Polg2 & $\begin{array}{l}5^{\prime} \text {-ACAGCAATCAGACACCCAG- } 3^{\prime} \\
5^{\prime} \text {-TTCTATTGGCTCCTTTCCCC-3' }\end{array}$ & 245 \\
\hline
\end{tabular}

per $\mu \mathrm{I}=\left(\right.$ amount of DNA in nanograms $\left.\times\left(6.022 \times 10^{23}\right)\right)$ / (length $\left.\times\left(1 \times 10^{9}\right) \times 650\right)$. The plasmids containing $m t-N D 1$ and rabbit globin were diluted to $9 \times 10^{7}$ copies/ $\mu$ and to $1 \mathrm{pg} / \mu \mathrm{l}$ respectively. Aliquots for single use were prepared and stored at $-20^{\circ} \mathrm{C}$.

\section{Quantification of $\mathrm{mtDNA}$}

All experiments were performed using a Corbett Rotor-Gene 6000 (Montreal Biotech, Montreal, QC, Canada). Each reaction tube contained $10 \mu \mathrm{l}$ FastStart Master SYBR Green Mix (Qiagen), $7 \mu$ sterile $\mathrm{ddH}_{2} \mathrm{O}, 1 \mu \mathrm{l}$ primers $(10 \mu \mathrm{M})$, and $2 \mu \mathrm{l}$ DNA template. Reaction conditions were $95^{\circ} \mathrm{C}$ for $5 \mathrm{~min}, 40$ cycles at $95{ }^{\circ} \mathrm{C}$ for $30 \mathrm{~s}, 60^{\circ} \mathrm{C}$ for $30 \mathrm{~s}$, and $72{ }^{\circ} \mathrm{C}$ for $30 \mathrm{~s}$. The final elongation step was $7 \mathrm{~min}$. A melting curve was analyzed to confirm that only one PCR product was generated.

To generate a standard curve for $m t-N D 1$, serial dilutions (five points, tenfold dilutions) were prepared using the plasmids containing rabbit globin cDNA and $m t-N D 1$. Each dilution was run in triplicate and three independent trials were run. Subsequently, one dilution of $m t-N D 1$ was run in the same reaction with the samples and used to determine the absolute mtDNA copy number in individual oocytes.

To prepare the oocyte DNA, 1 pg plasmid (4.1 kb) containing the rabbit globin cDNA and $20 \mu$ g glycogen were added to each microcentrifuge tube containing a single oocyte. DNA was purified using QIAmp DNA mini kits (Qiagen). Samples were eluted twice with $50 \mu$ l sterile water and used no more than 2 days after purification.

The primers used and the expected size of the amplified products are presented in Table 1. Primer sequences were obtained as follows: $m t-N D 1$ (Genbank NC_005089.1), Dr L C Smith (Université de Montréal); Polg, Polg2, Tfam, and Nrf1 (Thundathil et al. 2005); rabbit globin cDNA (Adjaye et al. 2007); and Actb (Arnold et al. 2008). All were obtained from Sigma.

\section{Drug treatments}

LY294002 (Sigma) was prepared as a 20 mM stock in dimethyl sulfoxide and used at $25 \mu \mathrm{m}$. Each day, half of the medium containing LY294002 was replaced with a medium containing freshly diluted drug. 


\section{RNA purification and CDNA synthesis}

One hundred oocytes were transferred to a microcentrifuge tube in a minimal volume of medium and $9 \mathrm{pg}$ rabbit globin mRNA (Sigma) was added. RNA was purified using a commercial kit (PicoPure; Arcturus Biosciences, Mountain View, CA, USA) and reverse transcribed using SuperScript II Reverse Transcription kit (Invitrogen). qPCR was performed as earlier, except that the following annealing temperatures used: Tfam and Polg2: $56{ }^{\circ} \mathrm{C} ; \mathrm{Nrf1}$ and Polg: $57^{\circ} \mathrm{C}$. 0.4 oocyte equivalents were used for each reaction. Samples not subjected to reverse transcriptase were used to confirm the absence of genomic DNA. Relative mRNA expression was calculated using the formula $2^{-\left(\Delta C_{\mathrm{t}} \text { sample}-\Delta C_{\mathrm{t}} \text { rabbit globin) }\right.}$.

\section{Statistical analysis}

Data were analyzed using the Student's t-test and one-way ANOVA followed by Tukey's HSD. Values are presented as mean \pm s.E.M. Regression analysis was performed using the function embedded in Microsoft Excel.

\section{Declaration of interest}

The authors declare no conflict of interest that could be perceived as prejudicing the impartiality of the research reported.

\section{Funding}

This work was supported by the Canadian Institutes for Health Research, the Natural Sciences and Engineering Research Council, the Royal Victoria Hospital Foundation, and the Government of Saudi Arabia (E Mahrous).

\section{Acknowledgements}

The authors thank Dr Daniel Dufort for advice on the manuscript.

\section{References}

Adjaye J, Herwig R, Brink TC, Herrmann D, Greber B, Sudheer S, Groth D, Carnwath JW, Lehrach H \& Niemann H 2007 Conserved molecular portraits of bovine and human blastocysts as a consequence of the transition from maternal to embryonic control of gene expression. Physiological Genomics 31 315-327. (doi:10.1152/physiolgenomics. 00041.2007)

Antelman J, Manandhar G, Yi YJ, Li R, Whitworth KM, Sutovsky M, Agca C, Prather RS \& Sutovsky P 2008 Expression of mitochondrial transcription factor A (TFAM) during porcine gametogenesis and preimplantation embryo development. Journal of Cellular Physiology 217 529-543. (doi:10.1002/jcp.21528)

Arnold DR, Francon P, Zhang J, Martin K \& Clarke HJ 2008 Stem-loop binding protein expressed in growing oocytes is required for accumulation of mRNAs encoding histones $\mathrm{H} 3$ and $\mathrm{H} 4$ and for early embryonic development in the mouse. Developmental Biology 313 347-358. (doi:10.1016/j.ydbio.2007.10.032)

Barritt JA, Kokot M, Cohen J, Steuerwald N \& Brenner CA 2002 Quantification of human ooplasmic mitochondria. Reproductive Biomedicine Online 4 243-247. (doi:10.1016/S1472-6483(10)61813-5)
Bogenhagen D \& Clayton DA 1977 Mouse L cell mitochondrial DNA molecules are selected randomly for replication throughout the cell cycle. Cell 11 719-727. (doi:10.1016/0092-8674(77)90286-0)

Cao L, Shitara H, Horii T, Nagao Y, Imai H, Abe K, Hara T, Hayashi J-I \& Yonekawa H 2007 The mitochondrial bottleneck occurs without reduction of mtDNA content in female mouse germ cells. Nature Genetics 39 386-390. (doi:10.1038/ng1970)

Clay Montier LL, Deng JJ \& Bai Y 2009 Number matters: control of mammalian mitochondrial DNA copy number. Journal of Genetics and Genomics 36 125-131. (doi:10.1016/S1673-8527(08)60099-5)

Cree LM, Samuels DC, de Sousa Lopes SC, Rajasimha HK, Wonnapinij P, Mann JR, Dahl HH \& Chinnery PF 2008 A reduction of mitochondrial DNA molecules during embryogenesis explains the rapid segregation of genotypes. Nature Genetics 40 249-254. (doi:10.1038/ng.2007.63)

Dumollard R, Duchen M, Carroll J \& St John JC 2007 The role of mitochondrial function in the oocyte and embryo. Current Topics in Developmental Biology 77 21-49.

Ebert K, Liem H \& Hecht $\mathbf{N} 1988$ Mitochondrial DNA in the mouse preimplantation embryo. Journal of Reproduction and Fertility 82 145-149. (doi:10.1530/jrf.0.0820145)

Ekstrand MI, Falkenberg M, Rantanen A, Park CB, Gaspari M, Hultenby K, Rustin P, Gustafsson CM \& Larsson NG 2004 Mitochondrial transcription factor A regulates mtDNA copy number in mammals. Human Molecular Genetics 13 935-944. (doi:10.1093/hmg/ddh109)

El Shourbagy SH, Spikings EC, Freitas M \& St John JC 2006 Mitochondria directly influence fertilisation outcome in the pig. Reproduction $\mathbf{1 3 1}$ 233-245. (doi:10.1530/rep.1.00551)

Herlands RL \& Schultz RM 1984 Regulation of mouse oocyte growth: probable nutritional role for intercellular communication between follicle cells and oocytes in oocyte growth. Journal of Experimental Zoology 229 317-325. (doi:10.1002/jez.1402290217)

Kameyama Y, Filion F, Yoo JG \& Smith LC 2007 Characterization of mitochondrial replication and transcription control during rat early development in vivo and in vitro. Reproduction 133 423-432. (doi:10. 1530/REP-06-0263)

Kang D, Kim SH \& Hamasaki N 2007 Mitochondrial transcription factor A (TFAM): roles in maintenance of mtDNA and cellular functions. Mitochondrion 7 39-44. (doi:10.1016/j.mito.2006.11.017)

Kanki T, Ohgaki K, Gaspari M, Gustafsson CM, Fukuoh A, Sasaki N, Hamasaki N \& Kang D 2004 Architectural role of mitochondrial transcription factor $\mathrm{A}$ in maintenance of human mitochondrial DNA. Molecular and Cellular Biology 24 9823-9834. (doi:10.1128/MCB.24. 22.9823-9834.2004)

May-Panloup P, Chretien MF, Jacques C, Vasseur C, Malthiery Y \& Reynier P 2005 Low oocyte mitochondrial DNA content in ovarian insufficiency. Human Reproduction 20 593-597. (doi:10.1093/humrep/ deh667)

May-Panloup P, Chretien MF, Malthiery Y \& Reynier P 2007 Mitochondrial DNA in the oocyte and the developing embryo. Current Topics in Developmental Biology 77 51-83. (doi:10.1016/S0070-2153(06)77003-X)

Piko L \& Taylor KD 1987 Amounts of mitochondrial DNA and abundance of some mitochondrial gene transcripts in early mouse embryos. Developmental Biology 123 364-374. (doi:10.1016/0012-1606(87)90395-2)

Pohjoismaki JL, Wanrooij S, Hyvarinen AK, Goffart S, Holt IJ, Spelbrink JN \& Jacobs HT 2006 Alterations to the expression level of mitochondrial transcription factor A, TFAM, modify the mode of mitochondrial DNA replication in cultured human cells. Nucleic Acids Research 34 5815-5828. (doi:10.1093/nar/gkl703)

Reynier P, May-Panloup P, Chretien MF, Morgan CJ, Jean M, Savagner F, Barriere P \& Malthiery Y 2001 Mitochondrial DNA content affects the fertilizability of human oocytes. Molecular Human Reproduction 7 425-429. (doi:10.1093/molehr/7.5.425)

Santos TA, El Shourbagy S \& St John JC 2006 Mitochondrial content reflects oocyte variability and fertilization outcome. Fertility and Sterility $\mathbf{8 5}$ 584-591. (doi:10.1016/j.fertnstert.2005.09.017)

Shoubridge EA \& Wai T 2007 Mitochondrial DNA and the mammalian oocyte. Current Topics in Developmental Biology 77 87-111. (doi:10. 1016/S0070-2153(06)77004-1)

Smith LC, Thundathil J \& Filion F 2005 Role of the mitochondrial genome in preimplantation development and assisted reproductive technologies. Reproduction, Fertility, and Development 17 15-22. (doi:10.1071/ RD04084) 
Spikings EC, Alderson J \& John JCS 2007 Regulated mitochondrial DNA replication during oocyte maturation Is essential for successful porcine embryonic development. Biology of Reproduction 76 327-335. (doi:10. 1095/biolreprod.106.054536)

Steuerwald N, Barritt JA, Adler R, Malter H, Schimmel T, Cohen J \& Brenner CA 2000 Quantification of mtDNA in single oocytes, polar bodies and subcellular components by real-time rapid cycle fluorescence monitored PCR. Zygote 8 209-215. (doi:10.1017/ S0967199400001003)

St John JC, Facucho-Oliveira J, Jiang Y, Kelly R \& Salah R 2010 Mitochondrial DNA transmission, replication and inheritance: a journey from the gamete through the embryo and into offspring and embryonic stem cells. Human Reproduction Update 16 488-509. (doi:10.1093/ humupd/dmq002)

Thundathil J, Filion F \& Smith LC 2005 Molecular control of mitochondrial function in preimplantation mouse embryos. Molecular Reproduction and Development 71 405-413. (doi:10.1002/mrd.20260)

Van Blerkom J 2009 Mitochondria in early mammalian development. Seminars in Cell and Developmental Biology 20 354-364. (doi:10.1016/ j.semcdb.2008.12.005)

Van Blerkom J 2010 Mitochondrial function in the human oocyte and embryo and their role in developmental competence. Mitochondrion 11 797-813. (doi:10.1016/j.mito.2010.09.012)

Wai T, Teoli D \& Shoubridge EA 2008 The mitochondrial DNA genetic bottleneck results from replication of a subpopulation of genomes. Nature Genetics 40 1484-1488. (doi:10.1038/ng.258)
Wai T, Ao A, Zhang X, Cyr D, Dufort D \& Shoubridge EA 2010 The role of mitochondrial DNA copy number in mammalian fertility. Biology of Reproduction 83 52-62. (doi:10.1095/biolreprod.109.080887)

Ylikallio E, Tyynismaa H, Tsutsui H, Ide T \& Suomalainen A 2010 High mitochondrial DNA copy number has detrimental effects in mice. Human Molecular Genetics 19 2695-2705. (doi:10.1093/hmg/ddq163)

Zeng HT, Ren Z, Yeung WS, Shu YM, Xu YW, Zhuang GL \& Liang XY 2007 Low mitochondrial DNA and ATP contents contribute to the absence of birefringent spindle imaged with PolScope in in vitro matured human oocytes. Human Reproduction 22 1681-1686. (doi:10.1093/humrep/ dem070)

Zheng W, Gorre N, Shen Y, Noda T, Ogawa W, Lundin E \& Liu K 2010 Maternal phosphatidylinositol 3-kinase signalling is crucial for embryonic genome activation and preimplantation embryogenesis. EMBO Reports 11 890-895. (doi:10.1038/embor.2010.144)

Zheng W, Nagaraju G, Liu Z \& Liu K 2012 Functional roles of the phosphatidylinositol 3-kinases ( $\mathrm{PI} 3 \mathrm{Ks}$ ) signaling in the mammalian ovary. Molecular and Cellular Endocrinology 356 24-30. (doi:10.1016/j.mce. 2011.05.027)

Received 28 March 2012

First decision 10 May 2012

Accepted 24 May 2012 